Review

\title{
Hypnosis for Resilience
}

Enrico Facco ${ }^{1,2,3, *}$

1. Studium Patavinum - Department of Neurosciences, University of Padua, Italy; E-Mail: enrico.facco@unipd.it

2. Science of Consciousness Research Group, Department of General Psychology, University of Padua, Italy

3. Institution F. Granone - Italian Center of Clinical and Experimental Hypnosis (CIICS), Turin (Italy)

* Correspondence: Enrico Facco; E-Mail: enrico.facco@unipd.it

Academic Editor: Giuseppe De Benedittis

Special Issue: $\underline{\text { Hypnosis: from Neural Mechanisms to Clinical Practice }}$

OBM Integrative and Complementary Medicine

2020, volume 5 , issue 3

doi:10.21926/obm.icm.2003032
Received: February 04, 2020

Accepted: April 17, 2020

Published: July 08, 2020

\begin{abstract}
The topic of resilience is of paramount importance. Although the term resilience was coined in the fields of physics and engineering, its use has spread to the fields of social sciences, biology, psychology, and psychiatry, as well as to the industry. Moreover, the term is now endowed with a wide range of meanings. The topic of resilience plays a central role in all critical life events. It is of paramount importance in medicine as well as in psychology and psychotherapy, where it is involved in both psychiatric disorders and physical diseases, particularly when encountering the specter of chronic pain, suffering, disability, and death. The available data indicate the relevance and effectiveness of hypnosis for resilience in numerous clinical conditions, and propose hypnosis as a candidate for a central role in palliative care. Furthermore, resilience is endowed with deep philosophical implications that are not to be neglected during patient management. Indeed, suffering, including the perception of one's doom as well as the real mystery of life and death, relies closely on philosophical, cultural, and ethnic factors. Eastern, as well as pre-Socratic philosophers, based their philosophies on an epistemologically sound, non-dualistic paradigm; they
\end{abstract}

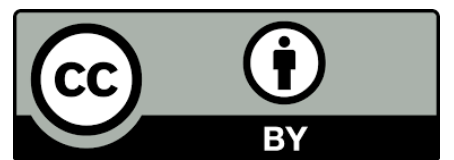

(c) 2020 by the author. This is an open access article distributed under the conditions of the Creative Commons by Attribution License, which permits unrestricted use, distribution, and reproduction in any medium or format, provided the original work is correctly cited. 
profoundly explored the inner-outer world relationship, allowing for so radical a resilience that has no equal in the modern Western culture. Therefore, these philosophies should be re-appraised and properly understood from a metaphilosophical perspective, in order to utilize their wisdom and knowledge in an efficient manner. A few examples of Eastern philosophical concepts drawn from Taoism, Yoga, and Buddhism, as well as those from Heraclitus and Parmenides, which would be potentially useful in patient care, are provided in the present article.

\section{Keywords}

Hypnosis; resilience; philosophy; epistemology; palliative care; Taoism; Buddhism; Yoga

\section{Introduction}

The topic of resilience, owing to its central role in all critical life events, is of paramount importance in the fields of medicine, psychology, and psychotherapy. The term 'resilience' was coined for physics, where it indicated an object able to recoil or spring back into shape after bending. In the context of an individual, resilience refers to the capacity to withstand or rapidly recover from difficult conditions such as those related to family and social relationships, financial stressors, workplace, and health issues.

The term resilience was derived from the Latin word resilire (which means to bounce), and in its broadest sense, it refers to the capacity of a system to adapt to the changes caused by external agents. The term was initially used in the fields of physics and engineering, and then its usage spread to the other fields such as social sciences, biology, psychology, and psychiatry, as well as to the industry, endowing the term with a wide range of meanings, a few of which are summarized as follows $[1,2]$ :

a) The capacity to absorb the deformation elastic energy and subsequently regain the initial shape (in materialss science).

b) Recovering the initial homeostasis following a perturbation or reaching a new state of balance through hallostasis (in biology).

c) A dynamic process of psychological adaptation, including both emotional and intellectual aspects as well as their management, in socio-cultural and environmental interactions.

d) Recovery from perturbation. In psychiatry, when dealing with psychopathic patients with no hope for recovery, resilience is limited to the restoration of the previous condition after it has worsened; for example, recovery from a phase of depression in a patient with severe bipolar disorder. Here, a relevant fact is the time of restoration, where resilience is the counterpart of vulnerability, i.e., it may decrease the proneness rather than preventing the susceptibility to psychopathy.

e) Useful resources for the management of change, i.e., self-transformation and enhanced awareness, which enable one to cope with changing living conditions.

f) Steady change of condition, including the amount of stress required to achieve it.

g) Conditioned resilience, yielded by prolonged treatment - e.g., improvement after the administration of psychiatric drugs, the effects of which may be for a limited duration. On 
the other hand, this could be considered a drug effect rather than actual resilience, unless it also favors a subject's change.

h) Dynamic balance, i.e., the average steady condition compatible with limited disturbances in a relatively steady condition; an example of a dynamic balance between the highs and lows in psychiatry could be borderline personality disorder.

The relevant elements of resilience are: a) threshold and feedback, b) functional redundancy and plasticity, c) management of the adaptation, and d) capacity and awareness. The threshold is defined as the level beyond which the requirement for a change is perceived, while positive or negative feedback may affect the response to critical events, in turn increasing or decreasing it, respectively. Redundancy is largely represented in biological systems and is defined as a property that allows preserving functions following damage. Management of the adaptation may occur through an interactive revision of the hypotheses and feedbacks, rather than simple trials and errors. Furthermore, in the world of business and risk management, resilience may be realized through reactive flexibility, i.e., the capacity to alter one's organization in response to environmental changes, or through proactive robustness, i.e., attempting to prevent crisis or decompensation, or to withstand the change, although possibly accompanied with minor changes or losses [3]. In both psychology and psychiatry, while reactive flexibility allows for second-order changes, the concept of proactive robustness is compatible with first-order changes.

As a matter of the relationship between the individual and the environment - between the inner and outer worlds in their unceasing becoming and transformation - resilience is mainly a cognitive problem, warranting the understanding of the meaning of reality, of what happens in its continuous dynamic change, and of the requirement for updating oneself to adapt to it. Resilience also calls for metacognition to properly understand: a) the meaning, value, and the limits of one's ideas, including the awareness of the mental process es employed to process these ideas; $b$ ) the limitations of the adopted Weltanschauung (view of the world) and Zeitgeist (spirit of times) in which all of us are immersed. In fact, the egocentric perspective of ordinary consciousness is unaware and inclined to naive realism (the belief that senses provide us with a direct awareness of the objects as they really are), where the ego is inclined to perceive the world as constituted of stable, separated objects with an autonomous intrinsic existence. As a consequence, despite being aware of the time stream, the ego is prone to believe that the outer world should remain unchanged and should always fit one's own expectations. This static view also forms the definition of identity, viz. its permanence in a ceaseless one's body and mind transformation, an unsolvable philosophical conundrum [4]. Therefore, any crisis, including the ones occurring in all periods of physiological changes in a lifetime, such as the transition from adolescence to the adult life, and then to aging, the role transitions, disasters, and diseases (with the associated specters of disability and death), becomes a powerful source of distress. This is not a matter of psychotherapy only, and rather, in the context of nature and the meaning of life and its becoming, belongs to philosophy, and, therefore, should be approached as a whole through an integration of both these disciplines.

The whole process of evolution of humankind, including culture, art, science, and technology, is a consequence of the encountered harms and crises. Indeed, fear and distress are powerful stimuli that force one to change, to cope, or to fail, whatever the case may be. Resilience is the virtue of all successful men that have ever lived, including the scientists (one for all, Stephen Hawking) and the artists (e.g., Beethoven, Chopin, Dostoevskij, Mussorgsky, Ravel, van Gogh, Messiaen) who perceived their diseases and disasters as resources, relentlessly continuing on their journey, 
providing humanity with beautiful works. An outstanding example is Olivier Messiaen, who was jailed in 1940 by the Nazis in the concentration camp Stalag VIII-A at Görlitz in Silesia. As he himself narrated, his only concern at the moment of his arrest was to get hold of a booklet regarding orchestral scores, a pencil, and a few music papers. When he underwent the check-up and wore the prison jumpsuit, he was terrified of the risk that his belongings were confiscated the only things, as he stated, that would have assisted him in bearing the hunger and cold that the soldiers themselves would have suffered from. Once there, he came across three other musicians who were playing strings and clarinet, and a malfunctioning piano. In the period of imprisonment, Olivier Messiaen composed the Quatuor pour la Fin $d u$ Temps, a masterpiece of the $20^{\text {th- }}$ century music, mainly while sitting in a latrine (the only quiet spot in the camp). The quartet was played on January 15, 1941, in a building of the camp, before all the prisoners and soldiers. The following month, Olivier was released, as a non-combatant soldier-musician. His religiosity and genius allowed him to transform an awful tragedy into a masterpiece. A common characteristic of all genius people in all the fields of human knowledge is the capacity to relentlessly work for moving on irrespective of the misfortunes, illnesses, and sufferings they may encounter, while the common man remains trapped within his limited horizon and ultimately collapses [5].

\section{Disease, Death, and Resilience}

Culture, the resulting Weltanschauung and Zeitgeist are at the base of the definition and the perceived relevance of all problems, including the terrific concepts of time and death. Indeed, both Weltanschauung and Zeitgeist are characterized by the incapacity of rational thought to be able to grasp their nature and meaning, despite the fact that time is now measured with incredibly high precision. Reflection on its nature has raised unsolvable aporias (logical contradictions) for over two millennia, and even in relativistic and quantum physics, its meaning and reality are under continuing debate [6-8].

It is noteworthy that the Chinese concept of time is considerably different from the Western one, the latter having been introduced in China at the end of $19^{\text {th }}$ century with a neologism. In Taoism, time is conceived as an unceasing renewal, duration, and opportunity - a concept grasped in the West by Bergson's philosophy of time. In Taoism, time - just as anything else - is a manifestation of Tao, which is characterized by the dynamic alternation and reciprocal generation of the two opposite although complementary poles, the Yin and the Yang. Accordingly, in Chinese language, verbs do not have past and future tenses, as the reality and the nature of existence is conceived as a stream, in which everything is transforming in a dynamic, immanent present $[9,10]$. This is also the reason for the absence of opposition between life and death, and as a consequence, the lack of soteriological doctrines, in the Chinese culture. Indeed, this clearly demonstrates that resilience in front of death - a human problem par excellence and the greatest source of anguish among humans - is essentially a matter of philosophy, and the causes for suffering rely closely on the adopted Weltanschauung. Similarly, Buddha was right when he stated that suffering stems from the five skhanda (the components of ordinary consciousness), while Epictetus, a Roman stoic philosopher of the first century A.C., stated that men do not fear things and rather the opinion they have of them [11].

Among all the sources of distress, death represents the greatest one, the mother of all the problems. In the clinical setting, the fear of diseases, pain, suffering, disability, and death is the 
main cause of anxiety disorders and depression. It is noteworthy that dental anxiety and phobia [which may also include symptoms of post-traumatic stress disorder (PTSD)] are significantly correlated to previous bad experiences associated with medicine and/or dentistry [12]. This may also justify the fear associated with all invasive procedures and medical therapies (such as chemotherapy and radiotherapy for cancer). Therefore, a bad doctor-patient relationship might be a cause of severe psychological disorders, turning the caregiver figure into a torturer.

Death has been the unsolved philosophical dilemma for ages, particularly in the West, and at the same time, the most powerful factor supporting both spiritual and material development of humankind. If mankind had been as resilient as not fearing death at all or anything else that could happen, perhaps there would not have been such advancements in science and technology, both of which stem from the will of having power and control on all possible harms [13]. Indeed, such an apparently unattainable level of resilience is that reached by the Taoist great man, as defined by Zhuāngzĭ $[6,7,14-16]$. The Western concept of time, with its rational, mathematical partition (past, present, and future), is the basis for profound anguish of the Western culture, which lies in the belief that everything is doomed to become nothing [17]. The resulting existential dilemma has led to huge religious, philosophical, and scientific developments, as analyzed by the Terror Management Theory and debated in contemporary philosophy between presentism and eternalism [18]. Nevertheless, the life-death problem remains unsolved so far, and the present time, ruled by a materialist monist perspective, is constitutionally unable to properly encounter this problem and accept the mystery associated with it.

According to Emanuele Severino, the Western culture is imbued with nihilism, which stems from the parricide of Parmenides by Plato and Aristotle and is marked by the idea that everything is doomed to become nothing- a questionable, ill-founded concept worth being deeply reappraised $[17,19]$. According to Parmenides, the being

"is, and that it is impossible for anything not to be. The other, namely, that which is not, and that something need not be, that, I tell you, is a completely untrustworthy path. For you cannot know what is not, that is impossible, nor can you utter it; for that can be thought and that can be is the same thing" (Perí Phýseōs, II, III).

In other words, ex nihilo nihil, i.e., from nihil, nothing can arise. Nihilism stems from Plato's conception of the world of ideas, where a concept of nihil may exist. However, it is an abstract positive concept of a negative fact which is self-contradictory, because, by definition, nihil cannot exist. As a consequence, Parmenides' parricide led to incorrectly considering phenomenal appearance for "being" and what disappears for nihil, a view similar to naive realism and disproved by modern physics as well. Indeed, energy cannot be destroyed, can change the form, while the matter is just a concentration of energy (according to the famous Einstein formula, $E=m C^{2} \rightarrow m=$ $E / C^{2}$ ). Therefore, even matter cannot turn into nothing. Furthermore, in quantum physics, matter is no longer considered the primary manifestation of the world and is rather thought to have manifested as a secondary product from quantum vacuum, rendering the materialist stance based on the classical concept of matter obsolete $[8,20]$. It is noteworthy that the reciprocal transformation between energy (yang) and matter (yin) had already been acutely defined by Taoism over two thousand years ago. In line with Taoism and Parmenides's thought, Hippocrates, the great father of medicine, stated in De Diaeta $(I, 4,9)$ that: 
"Nothing arises from nothing, rather everything changes due to mixture and separation. The men incorrectly think that things arise from the Hades and go back to the Hades, and therefore believe their eyes rather than reason. What is living cannot die, nor is it possible that what is not may begin to be".

In summary, the great wisdom of both Eastern philosophies and the Western pre-Socratic physicoi (philosopher-physicists) and physicians established that life is an inseparable life-death whole, i.e., death is nothing more than a transformation of life and an essential part of it, despite resembling the awful, irreconcilable opposite of this from the illusory, naive, egocentric perspective of ordinary consciousness. In this context, it is worth highlighting that the paradigms of Heraclitus, Parmenides, and Hippocrates were similar to that of Taoism [21], and the best way to translate the original Parmenides' concept of being into Chinese is, indeed, the term Tao [4]. Despite appearing as a metaphysical problem unworthy of attention from modern medical science, it has relevant epistemological implications in the science of consciousness as well as in the definition of the mind-brain-world relationship. The ancient thought also has greater compatibility with quantum physics compared to the classical Western post-Aristotelian thought (for a detailed analysis, see [7]), and the former is of paramount importance in therapy for improving resilience.

In the modern era, which is ruled by positivism and materialism, terminal illness and death have been reduced to a conventional matter of biological mechanisms, their technical management, and the political debate on their bio-ethical implications and resource availability. This inclination is paralleled by the neglect of death in everyday life, which is a defense mechanism that leads to an implicit illusion (or delusion) of immortality coupled to almost obsessive attention to health and physical efficiency. The ostensible obscenity of death and its neglect has been well-defined by Gorer as the pornography of death [22]. Death being an essential part of life rather than its opposite, the tragedy stems from the refusal to acknowledge it, engendered by the deceitful egocentric perspective: as Freud wisely stated paraphrasing a famous Latin motto on the war, si vis vitam para mortem (i.e., if you wish life, set up your death).

One must be aware that the adopted scientific concepts of health, normality, and disease are conventional and statistical in nature; although pragmatically useful, they are weaker than commonly believed and may turn against each other. According to Woodruff et al. [23], the disease may be defined as:

"any condition associated with discomfort, pain, disability, death, or increased liability to these states, regarded by the physicians and the public as properly the responsibility of the medical profession, may be considered a disease".

When considering the fact that we are all going to die one day, health may be paradoxically defined as an asymptomatic illness that would inescapably lead one to death, thereby fulfilling the above-stated definition of disease. The only difference between health and disease is the presence of symptoms and the possibility of diagnosis. Furthermore, suffering and pain may evoke in one, the awareness of one's actual existential condition. According to Le Breton, pain is not a plain symptom of disease, and is rather an incision of the sacred, ripping one from oneself and leading the one to confront one's limitations, the transience of life, and its cost. Pain obliges to metaphysics [24, 25].

If the above discussion is correct, the problems of life, disease, pain, suffering, and death are far from being a simple matter of medical definition from a narrow perspective of a positivist; these problems warrant a psychological and philosophical approach, with philosophy deserving a certain 
important place in both psychotherapy and hypnosis as well as in the patient-doctor relationship.

\section{Hypnosis for Resilience}

Resilience may be regarded as the key player in psychotherapy as well as the remedy for all sources of distress in both medicine and everyday life. This is the reason why the XIII Congress of the European Society of Hypnosis (held in Sorrento, Italy on October 21-25, 2014) was devoted to "Hypnosis and Resilience".

Hypnosis may effectively assist in restructuring patient's problems, an objective that David Spiegel has well-defined as "Trance-formation" [26]. Unlike psychotherapies which rely mainly on the retrospective analysis of the causes of disorders and their rational interpretation (such as psychoanalysis), hypnosis may additionally allow for direct experience in the "here and now" of the patient requirements and what they are seeking for through imagination and plastic monoideism [27-29]. Therefore, hypnosis may behave as a sort of simulator - a tool being increasingly employed in the training of pilots, surgeons, anesthetists, and all the professionals who require developing certain special skills.

Imagination has been understated or even disparaged by the century-old rationalist stance of Western culture. In fact, hypnosis was totally dismissed by the prominent panel of experts convened by King Louis XVI in France as "nothing but heated imagination" [30]. In early $20^{\text {th }}$ century, imagination was incorrectly considered a feature of the less-developed brain of children, primitive people, and inferior races, while conceptual thought was regarded as a privilege of the civilized, Western "superior" man - a sort of collective delusion of self-importance which led to the opprobrious consequences of colonialism and the ideologies of early $20^{\text {th }}$ century. In that positivist climate, Freud himself considered the visual images reported by his patients as related to their neurosis, which had to be replaced with a verbally-mediated rational analysis [31].

However, imagination is a powerful mind faculty that the great artists and scientists are endowed with. For instance, Nikola Tesla reported his incredible eidetic imagery in his autobiography, which allowed him to see with his mind eye all his inventions in complete detail, and even evaluate them prior to constructing them [32]. Albert Einstein, the icon of $20^{\text {th }}$ century science, was a scientist-philosopher who was endowed with a vivid imagination. In an interview to the Sunday Evening Post in October 26, 1929, he stated:

"I'm enough of an artist to draw freely on my imagination. Imagination is more important than knowledge. Knowledge is limited. Imagination encircles the world" [33].

The above-stated facts clearly demonstrate the relevance of imagination for knowledge and the century-old underestimation of imagination by the rationalistic Western culture. In the same years, young Milton Erickson, under complete paralysis following a severe case of polio, invented and taught himself a unique method of rehabilitation, playing mental games with himself, intensely wishing for and imagining playing outside, as well as watching his baby sister who was only learning to walk at that time.

The role and power of imagination have been recognized only recently in neuropsychology. Mental imagery (the "mind eye") is a multifaceted psychological construct that exhibits conceptual and neurobiological overlaps with related cognitive processes, such as attention, memory, and actual perception. Spatial imagery is associated with complex brain activation, including activations 
in the dorsolateral prefrontal cortex, visual cortex, middle frontal gyrus, premotor cortex, and parahippocampal gyrus [34]. Motor imagery facilitates motor performance, by training the associated brain areas and improving the association between process and actions, with the training exerting a long-lasting effect on metacognition [35]. These data also lead to a renewed interest in the potential use of motor imagery in rehabilitation [36-38], confirming the exceptional intuitions of the 17-year-old Milton Erickson one hundred years ago. Hypnosis enhances motor imagery by improving concentration and the connection between sensory information and motor output [39]. This is consistent with the relationship between hypnotic ability and the enhanced functional connectivity between the left dorsolateral prefrontal cortex (belonging to the executive control network) and the salience network (including anterior cingulate cortex, insula, amygdala, and ventral striatum), which allows the somatic, autonomic, and emotional information to be evaluated and integrated [40].

All these data suggest the relevance and effectiveness of hypnosis, with its plastic imagery, in both medical and psychological disorders. The neuropsychological components of the hypnotic simulator - a sort of mental lab - might allow one to virtually perform tasks, process information through a different perspective, and restructure one's problems with higher efficiency with respect to ordinary consciousness and a limited rational interpretation. This may occur without requiring a retrospective analysis of the distressing events of the past and would guide the patient in the present toward the future, updating his/her model of the world. The rational interpretation of past events, despite being undoubtedly useful, may not be sufficient for bringing a change; several patients have reported that it allowed them to understand the origin of their symptoms, although they anyway failed to overcome their limitations and recover.

According to Bandler \& Grinder [41], several patients are self-limiting because of their previous experiences and the resulting model of the world that they have developed, which prevented them from viewing and adopting new options and possibilities. This belongs to the physiology of life; even the oddest behavior, when observed from inside the subject's world, might turn out to be understandable and coherent with the subject's experience and adopted model. If so, an enlargement of patient's model, which would enable him/her to discover new paths and adopt new options and behavior, allows mitigating or even completely resolving the problem, rendering the previous limited behavior unnecessary. The updating and enlargement of the model is an issue of paramount importance in itself for the whole life. Bertrand Russell introduced an outstanding concept of Self enlargement, which encompassed philosophy, science, and psychology [4, 42]:

"All acquisition of knowledge is an enlargement of the Self... This enlargement of Self is not obtained when, considering the Self as it is, one attempts to demonstrate that the world is so similar to this Self that the knowledge of it is possible without any admission of what appears alien... Knowledge is a form of union of the Self and the not-Self; similar to all kinds of union, it is impaired by dominion, and consequently, by any attempt to force the universe into conformity with what one finds in oneself. This view... is untrue... What it refers to as knowledge is not a union with the not-Self, but a set of prejudices, habits, and desires, constructing an impenetrable veil between oneself and the world beyond. The man who has no tincture of philosophy goes through life imprisoned in the prejudices derived from common sense, from the habitual beliefs of his age 
or his nation, and from the convictions which have grown in his mind without the co-operation or consent of deliberate reason".

Therefore, an approach centered on the contemplation of the world beyond one's limited perspective, Weltanschauung and Zeitgeist in the "here and now" may strongly assist in developing resilience. This is not just useful for psychotherapy, rather is also an essential general rule in all the fields of human knowledge, including science, philosophy, and religion.

As far as therapy is concerned, resilience may be regarded as a relevant general component of the treatment, capable of enhancing coping irrespective of the causes of distress. At the same time, resilience removes the risk of possible retraumatization implied in the retrospective analysis of the distressing events.

Bandler and Grinder's model, as well as the psychoanalytic perspective, is compatible with the Solms and Panksepp's neuro-psycho-evolutionary approach, envisioning the evolution from an unconscious life to the first appearance of consciousness up to the development of the highest expression of the Self from a dual-aspect monist perspective [43, 44]. According to Solms and Panksepp's theory, emotions are dependent on the neurodynamics of the innate brain primary circuits yielding an anoetic form of consciousness, the neuro-anatomical base of which belongs to deep brain structures (including the brainstem, hypothalamus, central thalamic nuclei, and limbic circuits). Higher-order, noetic components of consciousness and awareness, as well as the autonoetic, autoreflective ones have their neuro-correlates in more rostral structures, the cerebral hemispheres. The ultimate result of this complex caudo-rostral circuitry is the bidirectional interplay between the anoetic and noetic components, which causes the present experiences to be affected by the past ones and the effects of past experiences to be consequently altered by the autoreflective processes of the present. The latter explains why it is possible to resolve the problems rooted in the past by working in the present to enlarge the patient's model, perspective, and the Self.

The outstanding properties of hypnosis allow it to a relevant tool in palliative care, where it may play a central role in enhancing coping and resilience. Here, resilience is used in its widest sense as the capacity to cope with all the adverse events and all the causes of suffering and pain; for instance, resilience here may also include hypnotic analgesia, which is not in itself a matter of resilience although it may improve resilience by means of enhancing one's ability to control pain. Hypnosis may be used beneficially in all the aspects of palliative care [45-47], including:

1. The management of anxiety, depression, and pain [48-50].

2. The peri-operative period of surgery and invasive procedures, where hypnosis may assist in relieving pre-operative anxiety and concern, improve wellbeing and collaboration, and enhance the stability of cardiorespiratory parameters). It may also improve post-operative wellbeing and wound recovery and may decrease the requirement for the intake of pain killers. It may even be successfully used as the only anesthesia in selected patients [51-54].

3. Physical symptoms, spontaneous or yielded by drug side effects, such as nausea and vomiting, diarrhea, flashes, insomnia, fatigue, and dyspnea [55]. It is noteworthy that most of the afore-stated symptoms could be caused or enhanced as a result of the nocebo effect, i.e., these could be psychosomatic in nature. For instance, a strong nocebo effect was reported in patients belonging to the placebo group in an RCT on cancer-related fatigue (including $79 \%$ insomnia and $38 \%$ nausea) [56]. In this context, hypnosis holds a great potential to assist in relieving the physical symptoms in patients even in severe pathologies 
such as cancer, where the psychosomatic components of suffering have greater relevance than previously believed.

The above-stated indications of hypnosis include a wealth of possible, specific suggestions and metaphors, a detailed description of which is far beyond the scope of the objectives of the present article. All these indications converge on the suggestion that resilience should be regarded as the key player in the whole management, which extends from the first diagnosis of chronic progressive disease all the way up to its terminal state. Hypnosis may assist in better confrontation overall and improve coping and resilience; this would be achieved through ego strengthening, mindfulness, usage of metaphors that assist in mitigating disturbing ideas, negative emotions, and any other causes of worry, and including the philosophical implications discussed above.

\section{Relevant Clues from Eastern Philosophies}

The above-discussed philosophical implications should not be regarded as abstract speculations. Rather, they are concrete, pragmatic reflections to be considered in clinical practice when dealing with distress, suffering, disease, and death. The modern medicine, with its governing mechanist-reductionist approach, has cured diseases rather than the patients, neglecting all the relevant subjective factors as if the mind would have no role to play in both health and disease, a fact that has huge epistemological implications [7, 21, 57]. Indeed, its paradigm is metaphysical in nature, stemming from the mathematical apriorism of Galileo and the original sin of Galilean Sciences, i.e., the compromise with the Church and Inquisition (which claim an exclusive competence on the soul), the genius of Descartes promoted through its radical dualism. Therefore, the novel sciences were epistemologically ill-founded as these were a consequence of political friction, which caused their field of interest to be forcibly limited to the Cartesian res extensa, and in medicine, to the earthen body machine. As a consequence, the observer was removed from the observed facts in the illusion of the neutrality of the former, and maintained so, until the revolution started in the $20^{\text {th }}$ century by quantum physics. Owing to its neglect of the consciousness and subjectivity, the positivist-materialist perspective governing medical science has been constitutionally unsuitable for properly understanding and managing the subjective phenomena, including pain and suffering.

Unlike the modern Western culture, Eastern philosophies have developed a profound knowledge regarding the inner world and its relationship with the external reality using a nondualistic perspective. It is noteworthy that according to the etymology of the term Yoga, a word that stems from the Sanskrit term yujir (binding together or joining), it indicates the reunion of mind and body, I and the non-I (i.e., mind-body-world), a state in which all the ostensibly opposite and incompatible phenomena are dissolved in an inseparable whole. Taoism and pre-Socratic philosophers, as well as Hippocrates, held the coniunctio oppositorum, i.e., convergence and reciprocal generation of the opposites. Over 2,000 years ago, Buddhism had already recognized and deeply analyzed the illusory stance of the Ego, the existence of the unconscious, the limitations of conceptual thought, the relevance of empathy and compassion, and the path of liberation from all the attachments and sorrows [14]. Together, all these belief systems established the path to wisdom and enlightenment, enabling one to live well, die well, and remain in a state of unshakable resilience, rather than seeking power from an egocentric utilitarian perspective. Therefore, according to the previously adopted approach to defining the Self [4], resilience may be 
better understood from a metaphilosophical perspective, by moving beyond the limited ethnocentric modern Western perspective and the positivist inclination to consider its concepts and findings as universal.

The discussion on metaphilosophical criteria and their application in the analysis of Eastern culture is far beyond the limited scope of an article (for further details, see [9, 58-62]). Therefore, the present article would just outline a few clues drawn from Buddhism and Taoism, in order to better understand their relevance in regard to resilience. The relevance of Eastern philosophy is also closely associated with the huge historical, procedural, and neuropsychological links between hypnosis and meditation [14, 16, 63-65], which have recently led to the introduction of what is referred to as mindful hypnosis $[66,67]$. Indeed, mindfulness meditation, which should be regarded as the best technique of Western meditation, is basically an adaptation of Vipassana meditation, while Śamatha meditation (meditation of the dwelling calm) is associated with hypnotic absorption and neutral hypnosis. Similar to hypnosis, dhāranā (the induction of yoga meditation) is based on focused attention and deep relaxation, while dhyāna (the meditative state) could be translated as meditative absorption and contemplation, which may engender a flow of images. Similarly, Buddhist meditation involves a detached observation of one's states and mental objects, and letting them go.

Eastern philosophers, unlike the Western ones, have unvaryingly merged theoretical philosophy and practical philosophy as a whole, devoting themselves to self-knowledge and the path for emancipation, i.e., liberation from all the attachments and conditioning, up to the level of wisdom, saintliness, and enlightenment. All the Eastern philosophies included meditation as an essential practice for reaching a complete metacognitive awareness and to get rid of $M \bar{a} y \bar{a}-$ the mask of illusion of the ordinary consciousness (i.e., the flawed naive realism and what Kant referred to as the unavoidable natural illusion $[4,57,68])$. Moreover, meditation, which allows for the subject's empowerment, may also serve as a healing technique.

As stated above, hypnosis has strong links to Eastern meditation [14, 16, 63-65]. In fact, the first mesmerists were deeply interested in the Eastern philosophies and healing practices, which they considered similar to their own discipline and claimed that Mesmer had only provided a scientific interpretation for these. In the early $19^{\text {th }}$ century, The Zoist, a journal on mesmerism, published several articles on Indian practices; hypnosis was also compared to Taoist practices and Yoga meditation (also referred to as hibernation), and was considered as an ecstatic or Mesmeric condition $[16,65]$. Neutral hypnosis may also favor intense experiences similar to those achieved with meditation and the ones associated with mystic and near-death experiences, such as "having no thoughts, being one with everything, increased meaningfulness, letting things happen, and merging with pure light or energy", among others [69-71].

Buddhism originated as a consequence of a pragmatic observation of reality, i.e., the universal presence of pain and suffering in the world. As Siddharta Gautama stated:

"Birth is pain, aging is pain; illness is pain; death is pain; attaching to what is displeasing is pain; separating from what is dear is pain; not obtaining what is wished for is pain. In brief, the five skhanda [the clusters of consciousness; author's note], which are the basis of the attachment to existence, are pain" (Samyutta Nikāya, 56, 11).

This apparently pessimistic cosmic view of pain is the starting point of the path to the most radical liberation from suffering, according to the Four Noble Truths (Majjhima Nikaya 26, 
Ariyapariyesana Sutta: The Noble Search). Therefore, both the stepping stone and the endpoint of Buddhism are akin to the essence of medicine and psychology, rendering Siddhartha Gautama the greatest psychotherapist in the history of humankind. The surprisingly modern viewpoint of Siddhartha Gautama recognized that the origin of suffering lies in the ordinary consciousness and ego. In brief, the path to liberation from suffering warrants overcoming the narrow limits and flaws along the path toward wisdom, a fact which also engenders the most radical resilience.

It is similar to Taoism. As Lăož stated, "the sage men are self-aware and not self-absorbed; selfrespect is not self-importance" [72]. Zhuāngzi defined the problem as follows:

"The perfect man has no self (Chapter 1)... Do not let your outward stance affect your inner self, nor allow your inner self to be drawn out (Chapter 4)... One who seeks fame and thereby loses his real self is no gentleman (Chapter 6)... The mean or petty person is willing to risk his very body for gain. The scholar risks his own self for fame... All of these different types, with differing claims to fame, have damaged their innate nature and risked their lives in the same way (Chapter 8)... Everyone in the world appears to be concerned only with his own self. This implies the whole world is full of anxiety (Chapter 14)" [4, 15].

The above-stated trait d'union between meditation and hypnosis allows certain valuable Eastern concepts to be exploitable in hypnotherapy; they include certain concepts from preSocratic philosophers, which share the non-dualistic paradigm of Taoism, based on the coniunctio oppositorum. Therefore, it would be worth outlining a few of these concepts prior to concluding the present article, which may assist in contributing to hypnotic suggestions and metaphors and/or could be included in the philosophical reflection outside the formal hypnotic sessions.

\subsection{Taoism \& Pre-Socratic Philosophy}

As stated earlier, the concept of Tao has an equivalent in the Parmenides' concept of being, while the Yin-Yang polarity appears tantamount to the Parmenides' light and dark night [4], as stated in the Perì Phýseos (VIII, 51-6):

"Henceforth, learn the opinions of mortals, listening to the deceptive ordering of my words. Mortals have settled in their minds, to speak of two forms, one of which they should have left out, and that is where they deviate from the truth. They have assigned an opposite to each, marked distinct from one another".

If the separation of the opposites is deceitful, the belief based on this separateness is a source of suffering, which leads one to anxiety in an endless attempt to escape from what is rejected or feared. Heraclitus, who properly described the dynamic course of events (also similar to the YinYang), wisely demonstrated how deceitful the ontological separation of the opposites is:

"Opposition unites. From what draws apart, emerges the most beautiful harmony. All the things occur by means of strife (DK 22B9)... Men do not know how something that is at variance agrees with itself. It is an attunement of opposite tensions, similar to that of the bow and the lyre (DK 22B52)... It is the same thing in us that is quick and dead, awake and asleep, young and old; the formerare shifted and become the latter, and the latter in turn are shifted and become the former (DK 22B89)... For god, all things are fair and good and just men suppose that certain things are unjust, while the others are just (DK 


\section{B103)... The disease makes health sweet and good; hunger, satiety; toil, rest}

(DK 22B112)".

When one completely understands that the opposites are not different, irreconcilable entities and rather just the complementary attributes of an inseparable deeper unit, the apparent bad part may be integrated in the whole along with the good one, and may be better accepted, despite remaining unpleasant; its intrinsic dynamics also emphasize its transience, both representing essential steps toward resilience. Indeed, nothing could be perceived and known without its opposite, not even pleasure without pain and good without evil. This was the initial condition of young Siddhartha Gautama, a crowned prince kept in the dark regarding the distressing events of life (disease, aging, and death), who began waking up when he realized the universal presence of pain in the world, and ultimately established the Buddhist way of liberation from it.

A further useful clue for resilience is provided by an ancient Chinese saying- "If you have a problem and there is a solution, what are you worried about? If you have a problem and there is no solution, what are you worried about?" The detached equanimity of the great Taoist man and his apparently unattainable resilience has been correctly defined by Zhuāngzĭ as follows [73, 74]:

"The titles and honors of this world are of no interest to him, nor is he concerned at the disgrace of punishments. He knows that there is no distinction between right and wrong, or between great and little. I have heard it been said that the Tao man earns no reputation, perfect Virtue is not followed, the great man is self-less'. In perfection, this is the path he follows... The perfect man is a pure spirit... He does not feel the heat of burning deserts or the cold of the vast waters. He is not frightened by the lightning which is capable of splitting open mountains, or by the storm capable of whipping up the seas... Neither death nor life concerns him; how could gain and loss disturb him? (Chapter 16)".

This absolute resilience also includes a non-spilt view of life and death in line with both Hippocrates and Heraclitus thoughts:

"Life follows death and death is the forerunner of life. Who can know their ways? Human life begins with the original breath; when it comes together, there is life, and when it is dispersed, there is death. As death and life are together in all this, which one of them should be termed as bad? All the forms of life are one, yet we regard some as beautiful, as they are spiritual and wonderful; others we count as ugly, as they are diseased and rotting. But the diseased and the rotting could become spiritual and wonderful, and the spiritual and the wonderful could become diseased and rotting. It is said that 'all that is under Heaven is one breath'. The sages always comprehend such unity (Chapter 22)".

These sentences, the wisdom of which is unquestionable, illustrate the mystery of life and death in a blissful manner, including their inseparability, and ultimately, the ontological inexistence of death, which is just a part of the dynamic process of life transformation. Death remains a tragedy for the ego; getting rid of the narrow, illusory perspective of the ego and contemplating the whole world as a ceaseless transformation of the "breath" (the Greek psyché, blow, energy), allows to view death to be not as bad as it appears from an egocentric, nihilistic, materialist perspective. 


\subsection{Patañjali's Yoga-Sūtra}

Nirodha and the internal witness are the two key concepts of Patañjali's Yoga-sütra, and the former allows disclosing the latter [75]. The term nirodha indicates an insight into the pure consciousness, which is void of any content (lying beyond perception, concepts, and any category of the mind). The ordinary consciousness is inclined to self-identification with mental objects (the inputs received from the outer and inner worlds) crossing one's mind, leading one to assume these and the related experiences as parts of oneself. The truth, however, is that the mind is their master and host; in itself, it is the pure awareness of the agent, the witness who observes phenomena and may choose to remain detached and untroubled.

Metaphorically (and this may be a hypnotic approach to assist the patient in understanding it), the flow of ordinary consciousness could be compared to an exposed film, where the images are the flow of experience, while nirodha could be recognized as that unexposed subtle stripe between subsequent images (their support), of which one is usually unaware [16]. Therefore, niroḍha is a meaningful step toward metacognition, which allows reaching a higher level of awareness and stability in encountering life's experiences. The internal witness is the detached neutral subject consisting of pure awareness, which enables one to control the activity of the ordinary consciousness, and recognize the nature of the mental objects and subsequently let them flow away without being conditioned by them; this was stated clearly by Patañjali in the following words:

"1.3. Yoga is the control (nirodha) of the modifications of the wave-vortex of mind activity (cittavrtti).

1.4. Then, the Seer abides in Itself, resting in its own True Nature, which is referred to as Self realization (tada drashtuh svarupe avasthanam).

4.5 While the activities of the emergent mind fields may be diverse, the one mind is the director of the many (pravritti bhede prayojakam chittam ekam anekesam)."

This wise analysis of the human mind by Patañjali is outstandingly profound and in perfect agreement with the concept of enlargement and complete realization of the Self [4].

\subsection{Buddhism}

Buddhism aims for a radical liberation from pain and suffering (dukkha), and the two key concepts of anicca and śūnyatā (the impermanence and the vacuity of reality, respectively) form its core. According to Buddhism, the world is not constituted of independent, separated "things" endowed with an intrinsic autonomous existence, and are rather interrelated transient events, the phenomenal appearance of which is the consequence of a co-creation of reality (unattainable in itself) and the human way of perceiving and coding it. Furthermore, Buddhism does not admit the existence of an Ego as a reified substance. Rather, the ego is conceived as a functional aggregate at the superficial layer of the empirical mind directed toward the outer world.

Buddhism, with its view of the world as constituted of interrelated events being in perfect agreement with quantum physics, is epistemologically sound and surprisingly modern [7, 20]. The relationship between the mind and the world described in Buddhism is consistent with the Pooper and Eccles' theory of the three worlds, a modified version of which is held by the author of the 
present article $[7,57,76]$. Furthermore, the nature of dukkha described in Buddhism is consistent with the present definition of pain in medicine, viz. a matter of experience rather than a plain epiphenomenon of stimulation of pain pathways in the nervous system [77-79]. This is equivalent to saying "no experience, no pain", a fact implying that pain could be well-managed by altering the experience. This definition is compatible with the observed outstanding analgesic effects of hypnosis, and exposes the self-contradictory overriding attitude of conventional medicine to rely just on drugs, which stems from its materialist-reductionist stance. A relevant aspect in the psychological management of suffering and pain (besides the hypnotic suggestions which are aimed at directly increasing the pain threshold [80]) is detachment from all the sources of sorrow by adopting a neutral, non-judgmental disposition. As emphasized by Siddhartha himself, suffering is closely related to the mismatch between what happens and what was expected:

"Birth is pain; aging is pain; illness is pain; death is pain; attaching to what is displeasing is pain; separating from what is dear is pain; not obtaining what is wished for is pain. In brief, the five skhanda [the clusters of consciousness], which are the basis for attachment to existence, are pain» (Samyutta Nikāya, 56.11).

Certainly, accepting does not necessarily imply approving or adopting a passive fatalist behavior. Rather, according to the Chinese saying stated earlier, acceptance allows for better coping with the life events, moving on to resolve problems when possible, and coming to terms with what is inescapable.

The proper approach to be followed is described well by the motto-“One must never mourn a paradise lost, rather live well even in hell". Paradise and hell are neither physical nor metaphysical places; they are just conditions of the mind. This is why, at first glance, the Indian concepts of samsāra (the world of becoming and suffering) and nirvāna (extinguishment) may appear as the irreconcilable opposites to the Western reader, similar to the concept of heaven and hell, which is rather not true. The Western reader may become disappointed upon discovering that samsära is nirvāna and nirvāna is samsara, the two different perspectives of human consciousness. Samsāra is the common inclination to focus on what is going awry, on what has been lost, thereby perceiving and depicting the outer world as hell. Nirvāna, being a non-judgmental stance, is to perceive everything (both good and bad things) without focusing on what has been lost, allowing for a fresh open-minded starting point that assists in discovering that good things are inseparably intermingled with the displeasing ones. For instance, the same beautiful sunset may be inspiring to an open mind that is ready to contemplate it, while it would be not be perceived as or deemed irrelevant by a worried mind that is focused on its own ordeal. Therefore, as Buddha stated, the source of suffering is in the ego and the ordinary consciousness, which have a narrow perspective.

The philosophical issues discussed above may appear odd or irrelevant to the modern view ruled by the clear-cut rationality of positive sciences. However, these philosophies are the expression of the several-thousand-year old thoughts of the great sage men, which should be reappraised and properly understood. Indeed, these thoughts belong to what Karl Jaspers referred to as the axial period (around 500 B.C., in the spiritual process extending from 800 B.C. to 200 B.C.) [81]:

"The most extraordinary events are concentrated in this period. Confucius and Lao-Tse were living in China, and all the schools of Chinese philosophy came into being... India produced the Upanishads and the Buddha, and similar to China, ran the whole gamut of philosophical possibilities down to sceptiscism, materialism, 
sophism, and nihilism in Iran, Zarathustra taught a challenging view of the world, as a struggle between good and evil; in Palestine, the prophets made their appearance... Greece witnessed the appearance of Homer, and of the philosophers Parmenides, Heraclitus, and Plato... Everything implied by these names developed during these few centuries, almost simultaneously in China, India, and the west, without any one of these regions knowing the others. What is new about this age is that man became conscious of the Being as a whole, of himself and his limitations. He experiences the terror of the world and his own powerlessness. He asks radical questions. Face to face with the void, he strived for liberation and redemption. By consciously recognizing his limits, he set for himself his highest goals. He experienced absoluteness in the depths of selfhood and in the lucidity of transcendence... Consciousness became, once again, conscious of itself; thinking became its own object... Spiritual conflicts arose... The most contradictory possibilities were essayed. Discussions... and the division of the spiritual realm into opposites... created unrest and movement, to the extent of spiritual chaos. As a result of this process, hitherto unconsciously accepted ideas, customs, and conditions were subjected to examination, were questioned, and liquidated. Everything was swept into the vortex."

In this inevitable process of reappraisal of the ancient thought, one must refrain from inadvertently adopting the ordinary ethnocentric, chronocentric, and egocentric Western perspective, which is conditioned by the axioms and theories adopted in the present Zeitgeist and the related traps of logic. In this context, it is worth emphasizing that science must not be confused with a narrow, acritical adoption of a given paradigm and set of [undemonstrated] axioms, the nature of which is metaphysical in nature - a fact which led Husserl to define the objectivism of positive sciences as a transcendental naivety worth of reappraisal [82]. Indeed, any rational discipline is based on undemonstrated axioms, and despite being valuable, remains dóxa (relative knowledge, opinion); Aristotle himself warned of the necessity of constantly wondering regarding the truthfulness of such axioms (Metaphysics 1005b, 1-5).

\section{Author Contribution}

The author is responsible for the entire process of writing up, revising, and approving the final version of this manuscript.

\section{Competing Interests}

The author has declared that no competing interests exist.

\section{References}

1. Angeler DG, Allen CR. Quantifying resilience. J Appl Ecol. 2016; 53: 617-624.

2. Angeler DG, Allen CR, Persson ML. Resilience concepts in psychiatry demonstrated with bipolar disorder. Int J Bipolar Disord. 2018; 6: 1-8.

3. Wieland A, Wallenburg CM. The Influence of relational competencies on supply chain resilience: A relational view. Int J Phys Distrib Logist Manag. 2013; 43: 300-320. 
4. Facco E, Al khafaji BE, Tressoldi P. In search of the true self. J Theor Philos Psychol. 2019; 39: 157-180.

5. Facco E. Esperienze di premorte. Scienza e coscienza ai confini tra fisica e metafisica. Lungavilla (PV): Edizioni Altravista; 2010. pp. 146-152

6. Taroni P. Filosofie del tempo. Il concetto di tempo nella storia del pensiero occidentale. Milano: Mimesis; 2012. pp. 397-398.

7. Facco E, Fracas F. L'enigma della coscienza. Milano: Mondadori; 2018. pp. 1

8. Fracas F. II mondo secondo la fisica quantistica. Segrate (Mlano): Sperling \& Kupfer; 2017.

9. Cabella M. Idee dell'umano tra Cina e Occidente. Genova, Italy: ECIG - Università; 2017.

10. Jullien F. II tmepo. Elementi di filosofia del vivere. Roma, Italy: Luca Sossella Ed.; 2002.

11. Epictetus, Torode S. The manual: A philospher's guide to life. UK: CreateSpace Independent Publishing Platform; 2017.

12. Facco E, Gumirato E, Humphris G, Stellini E, Bacci C, Sivolella S, et al. Modified dental anxiety scale: Validation of the Italian version. Minerva Stomatol. 2015; 64: 295-307.

13. Severino E. Legge e Caso. Mllano: Adelphi; 1980.

14. Facco E. Meditazione e Ipnosi tra neuroscienze, filosofia e pregiudizio. Lungavilla, PV, Italy: Altravista; 2014.

15. Zhuangzi. Zhuangzi. Indianapolis, US: Hackett Classics; 2009.

16. Facco E. Meditation and hypnosis: Two sides of the same coin? Int J Clin Exp Hypn. 2017; 65: 169-188.

17. Severino E. The essence of nihilism. Brooklin, NY: Verso; 2016.

18. Testoni I, Bisceglie D, Ronconi L, Pergher V, Facco E. Ambivalent trust and ontological representations of death as latent factors of religiosity. Cogent Psychol. 2018; 5: 1429349.

19. Severino E. Essenza del nichilismo. Mllano: Adelphi; 1982.

20. Wilczek F. The lightness of being: Mass, ether, and the unification of forces. New York, NY; 2010.

21. Facco E, Tagliagambe S. Ritornare a Ippocrate. In: Riflessioni sulla medicina di oggi. Milano, Italy: Mondadori; 2020.

22. Gorer G. The pornography of death. In: Death curr. Perspect., Palo Alto (CA): Mayfield; 1976, p. 71-76.

23. Woodruff RA, Goodwin DW, Guze SB. Psychiatric diagnosis. New York: Oxford University Press; 1974.

24. Le Breton D. Antropologia del dolore. Sesto San Giovanni, MI: Meltemi; 2007.

25. Le Breton D. Esperienze del dolore: Tra distruzione e rinascita. Torino: Raffaello Cortina Editore; 2010.

26. Spiegel D. Tranceformations: Hypnosis in brain and body. Depress Anxiety. 2013; 30: 342-352.

27. Granone F. Trattato di ipnosi. Torino: UTET; 1989.

28. Casiglia E. Trattato di ipnosi e altre modificazioni di coscienza. Padova, Italy: CLEUP; 2015.

29. Casiglia E, Finatti F, Tikhonoff V, Stabile M, Mitolo M, Gasparotti F, et al. Granone's plastic monoideism demonstrated by functional magnetic resonance imaging (fMRI). Psychology. 2019; 10: 434-448.

30. Spiegel D. Mesmer minus magic: Hypnosis and modern medicine. Int J Clin Exp Hypn. 2002; 50: 397-406. 
31. Thomas NJT. Supplement to mental imagery. European responses: Jaensch, Freud, and Gestalt psychology. 2010. Available from: Http://PlatoStanfordEdu/Entries/MentalImagery/European-ResponsesHtml

32. Tesla N. My Inventions: The autobiography of Nikola Tesla. Radford, USA: Wilder Publications; 2014.

33. Isaacson W. Einstein's god. In: Einstein, his life and universe. New York: Simon \& Schuster; 2007.

34. Sack AT, Schuhmann T. Hemispheric differences within the fronto-parietal network dynamics underlying spatial imagery. Front Psychol. 2012; 3: 214.

35. Rademaker RL, Pearson J. Training visual imagery: Improvements of metacognition, but not imagery strength. Front Psychol. 2012; 3: 24-33.

36. Wondrusch C, Schuster-Amft C. A standardized motor imagery introduction program (MIIP) for neuro-rehabilitation: Development and evaluation. Front Hum Neurosci. 2013; 7: 477.

37. Steenbergen B, Jongbloed-Pereboom M, Spruijt S, Gordon AM. Impaired motor planning and motor imagery in children with unilateral spastic cerebral palsy: Challenges for the future of pediatric rehabilitation. Dev Med Child Neurol. 2013; 55: 43-46.

38. Hoyek N, Di RF, Collet C, Hoyek F, Guillot A. The therapeutic role of motor imagery on the functional rehabilitation of a stage II shoulder impingement syndrome. Disabil Rehabil. 2014; 36: 1113-1119.

39. Muller K, Bacht K, Schramm S, Seitz RJ. The facilitating effect of clinical hypnosis on motor imagery: An fMRI study. Behav Brain Res. 2012; 231: 164-169.

40. Hoeft F, Gabrieli JD, Whitfield-Gabrieli S, Haas BW, Bammer R, Menon V, et al. Functional brain basis of hypnotizability. Arch Gen Psychiatry. 2012; 69: 1064-1072.

41. Bandler R, Grindler J. The strucutre of magic. Palo Alto: Science and Behavior Books; 1975.

42. Russell B. The value of phylosiphy. In: Problems of philosophy. Oxford, UK: Oxford University Press; 1912.

43. Panksepp J. Affective consciousness: Core emotional feelings in animals and humans. Conscious Cogn. 2005; 14: 30-80.

44. Solms M, Panksepp J. The "Id" knows more than the "Ego" admits: Neuropsychoanalytic and primal consciousness perspectives on the interface between affective and cognitive neuroscience. Brain Sci. 2012; 2: 147-175.

45. Facco E, Casiglia E, Zanette G, Testoni I. On the way of liberation from suffering and pain: Role of hypnosis in palliative care. Ann Palliat Med. 2018; 7: 63-74.

46. Elkins G, Fisher W, Johnson A, Sliwinski J. Clinical hypnosis for the palliative care of cancer patients. Oncology. 2012; 26: 26-30.

47. Marcus J, Elkins G, Mott F. A model of hypnotic intervention for palliative care. Adv Mind Body Med. 2003; 19: 24-27.

48. Thompson T, Terhune DB, Oram C, Sharangparni J, Rouf R, Solmi M, et al. The effectiveness of hypnosis for pain relief: A systematic review and meta-analysis of 85 controlled experimental trials. Neurosci Biobehav Rev. 2019; 99: 298-310.

49. Alladin A. Cognitive hypnotherapy for psychological management of depression in palliative care. Ann Palliat Med. 2018; 7: 112-124.

50. Alladin A. Cognitive hypnotherapy for accessing and healing emotional injuries for anxiety disorders. Am J Clin Hypn. 2016; 59: 24-46. 
51. Facco E. Hypnosis and anesthesia: Back to the future. Minerva Anestesiol. 2016; 82: 13431356.

52. Tefikow S, Barth J, Maichrowitz S, Beelmann A, Strauss B, Rosendahl J. Efficacy of hypnosis in adults undergoing surgery or medical procedures: A meta-analysis of randomized controlled trials. Clin Psychol Rev. 2013; 33: 623-636.

53. Facco E, Pasquali S, Zanette G, Casiglia E. Hypnosis as sole anaesthesia for skin tumour removal in a patient with multiple chemical sensitivity. Anaesthesia. 2013; 68: 961-965.

54. Potie A, Roelants F, Pospiech A, Momeni M, Watremez C. Hypnosis in the perioperative management of breast cancer surgery: Clinical benefits and potential implications. Anesthesiol Res Pract. 2016; 2016: 2942416.

55. Carlson LE, Toivonen K, Flynn M, Deleemans J, Piedalue KA, Tolsdorf E, et al. The role of hypnosis in cancer care. Curr Oncol Rep. 2018; 20: 93.

56. de la Cruz M, Hui D, Parsons HA, Bruera E. Placebo and nocebo effects in randomized doubleblind clinical trials of agents for the therapy for fatigue in patients with advanced cancer. Cancer. 2010; 116: 766-774.

57. Facco E, Lucangeli D, Tressoldi P. On the science of consciousness: Epistemological reflections and clinical implications. Explor J Sci Heal. 2017; 13: 163-180.

58. Pasqualotto G. East \& West. Venice, Italy: Marsilio Editori; 2008.

59. Jullien F. De l'etre au vivre. Lexique eurochinoise de la pensée. Paris, France: Gallimard; 2015.

60. Lazerowitz M. A note on metaphylosophy. Metaphilosophy. 1970; 1: 91.

61. Overgaard S, Gilbert P, Burwood S. An introduction to metaphilosophy. Cambridge University Press; 2013.

62. Weber R. "How to compare?" - on the methodological state of comparative philosophy. Philos Compass. 2013; 8: 593-603.

63. De Benedittis G. Neural mechanisms of hypnosis and meditation. J Physiol Paris. 2015; 109 : 152-164.

64. Holroyd J. The science of meditation and the state of hypnosis. AmJ Clin Hypn. 2003; 46: 109128.

65. Schmit DT. The mesmerists inquire about "oriental mind powers": West meets East in the search for the universal trance. J Hist Behav Sci. 2010; 46: 1-26.

66. Alladin A. Mindfulness-based hypnosis: Blending science, beliefs, and wisdoms to catalyze healing. Am J Clin Hypn. 2014; 56: 285-302.

67. Elkins G, Olendzkj N. MIndful hypnotherapy: The basics for clinical practice. New York, NY, US: Springer; 2019.

68. Kant E. Critique of pure reason. Cambridge, UK: CAmbridge University Press (1998); 1781.

69. Cardeña E, Jönsson P, Terhune DB, Marcusson-Clavertz D. The neurophenomenology of neutral hypnosis. Cortex. 2013; 49: 375-385.

70. Facco E, Casiglia E, Al Khafaji BE, Finatti F, Duma GM, Mento G, et al. The neurophenomenology of out-of-body experiences induced by hypnotic suggestions. Int J Clin Exp Hypn 2019; 67: 39-68.

71. Cardena E. The phenomenology of deep hypnosis: Quiescent and physically active. Int J Clin Exp Hypn. 2005; 53: 37-59.

72. Tzu L. Tao Te Ching. London, UK: Penguin Books Ltd.; 2009.

73. Palmer M. The book of Chuang Tzu. London: Penguin Books; 2006. 
74. Zhuāngzĭ (CHuang-Tzu). No Title. Milano: Adelphi; 1983.

75. Patanjali. The Yoga Sutras of Patanjali. NewYork, NY: North Point Press; 2009.

76. Popper KR, Eccles JC. The self and his brain. Berlin: Springer-Verlag; 1977.

77. Merskey H. The taxonomy of pain. Med Clin North Am. 2007; 91: 13-20.

78. Merskey H. Logic, truth and language in concepts of pain. Qual Life Res. 1994; 3: S69-S76.

79. Merskey H. Pain terms: A list with definitions and notes on usage. Recommended by the IASP subcommittee on taxonomy. Pain. 1979; 6: 249.

80. Facco E. Hypnosis as anesthesia for invasive procedures. In: Hypnosis for acute and procedural pain management: Favorite methods of master clinicians. Seattle, US: Denny Creek Press; 2019.

81. Jaspers K. The axial period. In: The origin and goal of history. Abingdon, Oxfordshire, UK: Routedge Revivals; 2011.

82. Husserl E. The crisis of european sciences and transcendental phenomenology: An introduction to phenomenological philosophy. Evanstone: Northwestern University Press; 1970.

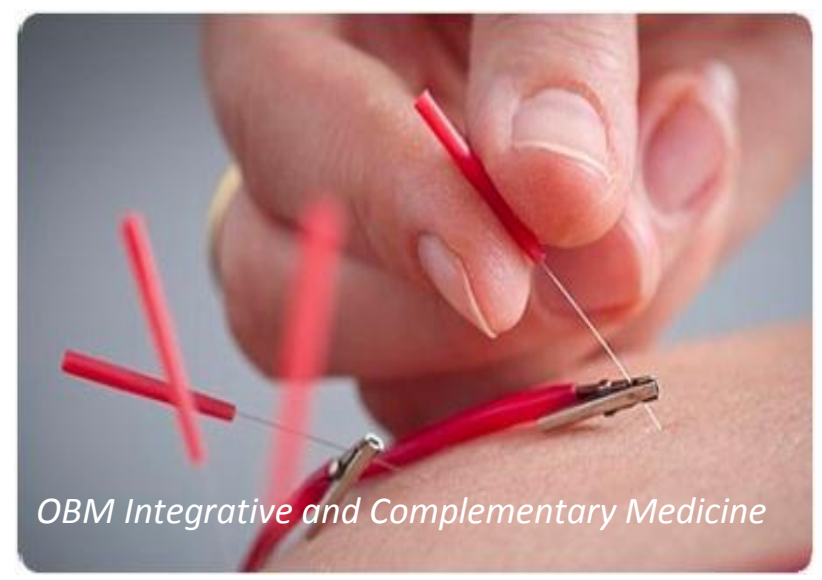

Enjoy OBM Integrative and Complementary Medicine by:

1. Submitting a manuscript

2. Joining in volunteer reviewer bank

3. Joining Editorial Board

4. Guest editing a special issue

For more details, please visit: http://www.lidsen.com/journals/icm 